\title{
Notas sobre la concepción de los sueños en el psicoanálisis relacional
}

\author{
André Sassenfeld J. \\ Santiago de Chile, Chile
}

Los sueños siempre han jugado un papel de gran importancia en la teoría y práctica del psicoanálisis desde sus inicios en la Interpretación de los sueños de Freud. Los teóricos relacionales, sin embargo, parecen haber hasta la fecha prestado poca atención sistemática a esta temática. Este trabajo recoge las contribuciones de los teóricos relacionales que sí han escrito sobre los sueños, partiendo por el trabajo pionero de Heinz Kohut, hasta llegar al trabajo de Robert Stolorow y George Atwood, James Fosshage y Philip Bromberg. Además, señala algunos más aspectos generales de cómo el psicoanálisis relacional entiende los sueños.

Palabras clave: sueños, hermenéutica, perspectiva relacional

Dreams have always played an important role in the theory and practice of psychoanalysis from its beginnings with Freud's Interpretation of Dreams. Relational theorists, however, seem to date to have payed scarce systematic attention to this topic. This article takes up the contributions of relational theorists that have written about dreams, from Heinz Kohut's pioneering work, to the work of Robert Stolorow and George Atwood, James Fosshage and Philip Bromberg. It also highlights some more general aspectos of how relational psychoanalysis understands dreams.

Key Words: dreams, hermeneutics, relational perspective

English Title: Notes on the conception of dreams in relational psychoanalysis

\section{Cita bibliográfica / Reference citation:}

Sassenfeld J., A. (2020). Notas sobre la concepción de los sueños en el psicoanálisis relacional. Clínica e Investigación Relacional, 14 (1): 133-162. [ISSN 1988-2939] [Recuperado de www.ceir.info ] DOI: 10.21110/19882939.2020.140109 
Los sueños han ocupado desde los inicios del psicoanálisis un lugar de particular importancia tanto teórica como clínicamente, lugar que es posible equiparar al lugar que los sueños han ocupado en la historia antigua de la humanidad (por ejemplo, en la Biblia, etc.). En la historia de la humanidad, ciertos sueños y su interpretación determinaron la toma de decisiones que afectaron el destino de naciones enteras; esa era la seriedad con la cual ciertos personajes históricos abordaban al menos ciertos sueños. Freud (1900) los colocó como via regia a lo inconsciente en el centro del psicoanálisis entendido como ciencia de lo inconsciente. En efecto, para algunos psicoanalistas, el psicoanálisis como disciplina se inaugura con la publicación de La interpretación de los sueños en 1899. Desde este punto de vista, asumo que el interés de cualquier psicoterapeuta analítico se agudiza cuando un paciente relata un sueño ya que se trata de una de las manifestaciones inconscientes más emblemáticas y al mismo tiempo más directas y ricas en términos de contenidos psicológicos ajenos a la consciencia. Se trata de una especie de vistazo (casi) no mediado por la consciencia al mundo psíquico inconsciente. Al menos para Freud, así como para muchísimos analistas posteriores, trabajar con sueños era una parte fundamental de cualquier trabajo analítico sistemático.

Frente a este somero trasfondo de un aspecto central de la tradición psicoanalítica histórica, sorprende la relativa escasez de publicaciones relacionales que aborden la temática de modo directo. Por supuesto, contamos con artículos relacionales que hacen referencia a algún sueño de algún paciente. No obstante, hasta donde alcanzan mis conocimientos, no existe hasta ahora por ejemplo un libro propiamente relacional dedicado a los sueños en particular. Por ende, estamos frente a la interrogante respecto de si acaso y, de ser así, cómo se ha transformado la concepción psicoanalítica contemporánea de los sueños. En realidad, no es posible creer que la concepción relacional de los sueños no ha cambiado respecto de la concepción freudiana ya que la comprensión freudiana de los sueños se basa en la teoría pulsional que el psicoanálisis relacional ha abandonado (Mitchell, 1988). Recordemos que en la obra de Freud los sueños representan el cumplimiento de un deseo inconsciente que tiene raíces profundas en el mundo pulsional del individuo. "En consistencia con la totalidad de su teoría de la personalidad, Freud ancló su hallazgo clínico de deseos latentes en los sueños en un modelo metapsicológico, esto es, el modelo pulsióndescarga, dominado por los modelos biológicos y fisicalistas de su época" (Fosshage, 1988, p. 162). El comentario de James Fosshage se asemeja al tipo de crítica epistemológica, filosófica y teórica que numerosos teóricos relacionales han formulado a diferentes aspectos del psicoanálisis freudiano.

El teórico interpersonal Mark Blechner $(2001,2018)$ ha escrito de modo sistemático sobre sueños y mi intento de articular los aspectos fundamentales de la concepción psicoanalítica relacional de los sueños en este trabajo recoge de sus ideas, y de las anteriores de Robert Gaines (1994), especialmente la necesidad de tomar en serio ciertos conceptos de Carl Gustav Jung sobre 
los sueños (véase, también, Giannoni, 2003). Tal como Gaines señala, existen muchos elementos comunes entre la psicología analítica jungiana y el psicoanálisis interpersonal a la hora de comprender los sueños. Y la perspectiva interpersonal es una de las perspectivas analíticas más cercanas al pensamiento relacional. En realidad, junto a la psicología del self, es una de sus matrices de origen (Sassenfeld, 2019a). Al rescatar ciertas ideas de Jung, creo poder aportar a que al igual que ocurrió con la obra de Sandor Ferenczi, Jung deje de ser un fantasma y se convierta en un ancestro del psicoanálisis relacional -por hacer uso de la poética descripción que Hans Loewald (1960) hizo de la tarea del psicoanálisis.

(I) ¿Qué es un sueño? Aún siendo psicoterapeutas analíticos, pocas veces nos detenemos en una interrogante tan básica como esta. Los sueños son los sueños y, además, son para muchas personas "nada más que un sueño". Para algunos, se trata del resultado de conexiones sinápticas fallidas que se producen mientras dormimos. Las neurociencias cognitivas están cada vez más convencidas de que soñar cumple la función de consolidar la memoria, entre otras cosas (Fosshage, 1997). Psicológicamente, sin embargo, el psicoanálisis no puede detenerse o darse por satisfecho frente a afirmaciones generales como estas. De hecho, Freud no lo hizo y desarrolló una comprensión psicoanalítica de los sueños $y$, con ello, asumió que un sueño es un fenómeno psicológico. Ello nos puede parecer evidente hoy en día, pero en la antigüedad un sueño podía ser interpretado como un mensaje de los dioses. En Freud, en términos amplios quizás estaría justificado afirmar que un sueño es la realización disfrazada de un deseo que la consciencia es incapaz de admitir. Dado que la consciencia es incapaz de admitir ese deseo, el sueño lo retrata en una forma distorsionada que es el resultado del denominado trabajo de sueño, que emplea mecanismos como el desplazamiento y la condensación. Como señalé en la introducción, esta concepción depende de la teoría pulsional en la medida en la que ciertas pulsiones -deseosconforman el "material" psíquico que origina un sueño.

De la teoría pulsional también depende la conocida distinción freudiana entre contenido latente y manifiesto (Fosshage, 1983), de acuerdo a la cual el sueño tal como es recordado por el individuo -su contenido manifiesto- no es lo que es, sino que disfraza su verdadero contenido -su contenido latente inconsciente, que siempre está dado por un deseo pulsional conflictivo. Como veremos en lo que sigue, el psicoanálisis relacional se ha alejado de esta distinción freudiana. Blechner (2001) comenta al respecto:

Nuestros sueños no están preocupados principalmente con disfrazar y censurar. De hecho, son nuestras comunicaciones más honestas, quizás la única comunicación humana en la que no podemos mentir. Podemos mentir sobre nuestros sueños, pero no en nuestros sueños. [...] Siempre decimos la verdad en nuestros sueños, aunque su mensaje puede no ser accesible a todos. Debido a que los sueños representan la verdad a través de medios que difieren de 
nuestros pensamientos despiertos, su significado puede ser poco claro para el soñante. $Y$ puesto que el mensaje puede ser algo que está disociado para el soñante, esta puede no ver el significado que puede ser obvio para una persona que no tiene la necesidad de disociar el mismo contenido. (p. 50, cursivas del original)

Blechner destaca que los sueños ni están ocultando cosas ni tampoco están hechos para ser comprendidos con facilidad. Más bien, hablan su propio idioma "que está diseñado para ser significativo sin necesariamente ser comunicativo" (p. 50). Su cualidad significativa es lo que los convierte en un fenómeno hermenéutico, esto es, en un fenómeno necesitada de comprensión interpretativa.

En el psicoanálisis relacional, la concepción freudiana recién descrita forma parte de lo que el fenómenologo hermenéutico francés Paul Ricoeur (1965) y después de él Donna Orange (2011) llaman hermenéutica de la sospecha (véanse también Sassenfeld, 2012a, 2016, 2019a y ScottBaumann, 2009). Una hermenéutica es una cierta manera o un cierto marco básico de referencia para interpretar y con ello comprender la experiencia subjetiva, incluyendo los sueños en cuanto experiencias subjetivas. En la hermenéutica de la sospecha, característica del psicoanálisis clásico, predomina la idea de que lo que aparece en un primer plano es una ocultación de lo genuino que subyace "detrás" de lo aparente. En términos de un sueño, "detrás" del contenido manifiesto se encuentra el contenido latente, considerado por lo común más profundo y verdadero. Y, para acceder a este, hace falta de parte del analista una actitud de sospecha respecto de lo aparente y manifiesto. Ricoeur incluyó entre los "maestros" de la hermenéutica de la sospecha a Karl Marx, Friedrich Nietzsche y Sigmund Freud, quienes cada uno a su manera contribuyó a develar estructuras determinantes que subyacen a la experiencia subjetiva e intersubjetiva más aparente, consciente y cotidiana. El psicoanálisis clásico en sí mismo en cuanto sistema teórico-práctico puede ser visualizado como una hermenéutica de la sospecha; por ejemplo, clínicamente el concepto central de resistencia es una plena expresión de ello. El paciente se resiste cuando es incapaz de reconocer un aspecto inconsciente que el psicoterapeuta ha podido reconocer gracias a su actitud de sospecha. En otro lugar, tanto Orange (2011) como yo (2016) hemos descrito en detalle las consecuencias de una actitud de sospecha por parte del terapeuta para la relación analítica y el trabajo clínico.

En contraste con esta perspectiva psicoanalítica tradicional, lo que he llamado el giro fenomenológico en el psicoanálisis contemporáneo (Sassenfeld, 2019a) -un vuelco hacia la experiencia vivida- nos presenta una forma del todo distinta de contemplar la realidad onírica. Colapsando la distinción entre contenido latente y manifiesto -que en el psicoanálisis relacional a mi parecer no existe-, ya en 1945 Jung definió el sueño como auto-retrato espontáneo de la situación actual de lo inconsciente en forma simbólica. En otras palabras, un sueño es una expresión del mundo subjetivo del soñante que deja entrever aspectos centrales de lo que al 
soñante le está ocurriendo subjetivamente. Es más, el sueño no se limita a hacer visible lo que al soñante le está ocurriendo. Tal como detallaremos en un punto posterior con mayor detalle, la experiencia onírica deja en evidencia la forma típica de organización del mundo subjetivo del soñante porque es una experiencia más de ese sujeto en particular. Ahora bien, cuando Jung alude a la forma simbólica del sueño, en mi opinión hace referencia a lo que Erich Fromm (1951) denomina el lenguaje olvidado en el cual los sueños así como los cuentos de hadas y los mitos se expresan. Blechner (2001) señala en este sentido que "el sueño no está preocupado de la comunicabilidad" (p. 9, cursiva del original), sino que se expresa en un lenguaje que nos resulta ajeno. Hemos olvidado cómo entender ese lenguaje en imágenes a ratos extraño, bizarro e irracional -por mucho que nos continúa impactando a menudo de modo potente- aunque es inherente a nuestra psique -brota de ella todas las noches, recordemos o no. Al desaparecer la distinción entre contenido manifiesto y contenido latente, el sueño se convierte en un fenómeno en el sentido propiamente fenomenológico del término: algo que aparece y que se nos muestra desde sí mismo como lo que es.

En concordancia con el giro fenomenológico del psicoanálisis contemporáneo -siendo que se declaró tempranamente un fenomenólogo psicoanalítico- Jung fue sistemático en enfatizar que un sueño es una experiencia. ¿Qué significa eso? Entre otras cosas, que lo que uno vive en un sueño no es tan solo "nada más que un sueño", sino algo que uno efectivamente experimentó por mucho que lo haya experimentado en una forma diferente a lo que llamamos nuestra experiencia cotidiana despierta y por mucho que su impacto y sus efectos pueden variar ampliamente respecto de nuestra experiencia cotidiana despierta. Por supuesto, se trata de algo que uno experimentó no en un sentido literal, pero que aún así vivenció en la realidad psíquica -lo cual en ningún sentido le quita el estatus de experiencia. Tal como indica Philip Bromberg (2006), un sueño debe concebirse "como un espacio real en el cual el paciente ha estado" (p. 39). Hay sueños tan vívidos, que el soñante puede llegar al menos por un momento a perder la claridad de que se trató de un sueño y no de una experiencia despierta. De hecho, por lo general un paciente comienza el relato de un sueño de la misma manera en la que relataría otro tipo de experiencias. En este sentido, lo que ocurre en un sueño es algo que a uno le pasó, es parte de lo que hemos vivenciado por mucho que la consciencia lo califique de una manera diferente a la que califica la mayor parte de las experiencias que atraviesa. Asumir que un sueño es siempre ya una experiencia vivida implica que en primer lugar no se requiere la adopción de una actitud de sospecha con la finalidad de llegar al contenido latente. Más bien, implica acoger el sueño tal como acogeríamos cualquier otra experiencia relatada -una actitud que en el psicoanálisis relacional está vinculada con la llamada hermenéutica de la confianza (Orange, 2011; Sassenfeld, 2012a, 2016, 2019a).

En un fuerte contraste con la hermenéutica de la sospecha, la hermenéutica de la confianza -basada en la hermenéutica filosófica dialógica de Hans-Georg Gadamer (Orange, 1995, 2010, 
2011; Sassenfeld, 2010a, 2012a, 2016, 2019a; Stern, 1997)-toma como punto de partida la idea de que el relato que el paciente hace del sueño no intenta ocultar ni disfrazar nada. Es simplemente la mejor manera que el paciente tiene en ese momento de hablar acerca de una determinada experiencia subjetiva. Confiamos en que tanto el sueño como el paciente se expresan de la mejor forma que pueden y que es tarea conjunta de paciente y psicoterapeuta encontrar sentido a lo que un sueño muestra y a lo que se muestra en este (Buirski \& Haglund, 2001; Orange, 1995). Es decir, el paciente no es concebido como antagonista, aunque sea un antagonista inconsciente, sino como un desconocido que sufre y que, por ende, necesita de hospitalidad clínica (Orange, 2011, 2016). La hermenéutica de la confianza, sin embargo, no debe entenderse como ingenua; no se contrapone a la hermenéutica de la sospecha como alternativa excluyente, sino que la engloba. En el seno de la hermenéutica de la confianza es posible sospechar, solo que sospechar se entiende como la posibilidad siempre presente de asumir que el sueño puede tener más de un significado, en realidad de que invariablemente tiene múltiples significados. La formulación consciente de algunos de ellos puede generar "resistencia" en el paciente y/o en el terapeuta porque tales significados generan angustia, ira, miedo, etc. $y$, en esa medida, requieren de un proceso de elaboración más detenido. Jung creía, en ese sentido, que la idea freudiana de que el sueño oculta contenidos era en el fondo una racionalización proyectiva de la propia experiencia de Freud de sentirse incapaz de comprender (véase Gadamer, 1972) ${ }^{1}$.

Ha quedado en evidencia en este primer punto que existen ciertas correspondencias entre la manera en la que se concibe lo que un sueño es y la actitud que se adopta para acercarse a este -al menos eso se tiende a observar cuando contrastamos el psicoanálisis clásico y el psicoanálisis relacional. Tales diferencias guardan a mi parecer una relación fundamental con la actitud que el psicoanálisis clásico por un lado y el psicoanálisis relacional y la psicología analítica jungiana por otro lado tienen respecto de lo inconsciente (véanse Beebe, 1997 y Safran, 2006). La teoría pulsional tradicional de lo inconsciente con sus diversas derivadas intrapsíquicas, grupales, antropológicas y socioculturales en la obra de Freud ve en lo inconsciente un adversario; solo cabe recordar la idea de Freud (1933 [1932]) de lo inconsciente como una caldera llena de excitaciones pulsionales que el individuo tiene que aprender a controlar. La actitud que los teóricos relacionales adoptan respecto de lo inconsciente es muy diferente a la freudiana y se asemeja más a la jungiana: en palabras de Jeremy Safran (2006), en los escritos relacionales se percibe "un inconsciente creativo y generativo más que un inconsciente que es peligroso y destructivo" ( $p$. 394), quedando en evidencia que lo inconsciente es "una fuente importante de sentido, vitalidad y creatividad" (p. 399). En ello, el psicoanálisis relacional y las neurociencias afectivas contemporáneas coinciden en alguna medida. En una publicación reciente, Antonio Damasio (2010) aseveró que el conocimiento no consciente que trae consigo todo organismo biológico "es 
bastante sofisticado y no debería ser considerado primitivo. La complejidad de este conocimiento es enorme y su aparente inteligencia notable" (p. 69).

(II) En la historia del psicoanálisis, la concepción de los sueños empezó a transformarse profunda y explícitamente entre otras cosas con el surgimiento de la psicología del self, una de las matrices de origen del psicoanálisis relacional (Sassenfeld, 2019a). Cuando Heinz Kohut (1971, 1977, 1984) comienza a articular una comprensión fenomenológica de la subjetividad abandonando lo que le parecían teorías metapsicológicas distanciadas de la experiencia subjetiva misma, también su entendimiento de los sueños cambió. Buscó encontrar teorías analíticas capaces de mantenerse cercanas a la experiencia directa e inmediata, con lo cual debe contarse entre los fenomenólogos psicoanalíticos en ciernes. Con la compleja dificultad que las lealtades interiores y exteriores así como los asociados -y justificados (Orange, 2020; Sassenfeld, 2019a)- temores de exclusión que tantos teóricos psicoanalíticos creativos han experimentado introduce, Kohut empezó a distinguir entre dos tipos de sueños: por un lado, los "sueños freudianos" típicos y, por otro lado, lo que denominó sueños del estado del self. En otras palabras, diferenció entre sueños que expresan "contenido latente verbalizable (deseos pulsionales, conflictos e intentos de solución de conflicto [...]" (1977, pp. 108-109)

y aquellos que intentan con ayuda de imaginería onírica verbalizable ligar las tensiones noverbales de los estados traumáticos (el temor a la sobre-estimulación o a la desintegración del self [psicosis]). Los sueños de este segundo tipo retratan el temor del soñante frente a algún aumento incontrolable de tensión o su temor a la disolución del self. El mismo acto de retratar estas vicisitudes en el sueño constituye un intento de manejar el peligro psicológico cubriendo atemorizantes procesos sin nombre con imaginaría visual nombrable. (p. 109)

La contribución esencial de Kohut (1977) en el contexto de este trabajo por supuesto está dada por los por él llamados sueños del estado del self. Él mismo relaciona esta forma de visualizar los sueños con la dimensión de lo traumático, esto es, con la representación psíquica de hondas angustias de desintegración y fragmentación del self. Una paciente mía soñaba por ejemplo que caminaba por un campo repleto de animales despedazados. En efecto, para Kohut el "mismo acto de retratar estas vicisitudes en el sueño constituye un intento de manejar el peligro psicológico cubriendo procesos atemorizantes sin nombre con imaginería visual nombrable" (p. 109). Con ello, Kohut atribuye al sueño, junto a teóricos analíticos como Wilfred Bion, la función de procesar elementos traumáticos de la experiencia. Al asumir esta postura, en plena congruencia con la teoría psicopatogénica traumatocéntrica del psicoanálisis relacional, a diferencia de lo que se supondría que sería clínicamente correcto hacer con sueños "freudianos" -seguir las asociaciones libres del paciente hasta dar con el contenido latente e interpretarlo-, los sueños del estado del self llevan en otra dirección. En el mejor de los casos, siguiendo a Kohut, la asociación libre en 
torno a uno de estos sueños "nos proporciona más imaginería que permanece en el mismo nivel que el contenido manifiesto del sueño" (p. 109). Esto es, las asociaciones del paciente no conducirán a "mayor profundidad" inconsciente en comparación con el contenido manifiesto del sueño, sino que redundarían en lo que significa el sueño como tal.

Desde este punto de vista, Kohut (1977) considera que el sueño manifiesto y sus asociaciones elaborativas nos permiten "reconocer que los sectores sanos de la psique del paciente están reaccionando con ansiedad frente a un cambio perturbador en la condición del self [...] o frente a la amenaza de disolución del self" (p. 109). Así, desde el punto de vista de la psicología del self en los sueños del estado del self aparecen estados arcaicos del self junto a sus correspondientes angustias primitivas de forma no disfrazada. Por lo tanto, el contenido de tales sueños no guarda relación con un deseo inconsciente y el conflicto intrapsíquico que este provoca, sino con una explicitación de un estado psíquico que tiende a la fragmentación o que ya se encuentra en esta a través de imaginería onírica generada por lo que el mismo Kohut llama los "sectores sanos" de la psique. Como ha ocurrido tantas veces en la historia del psicoanálisis, un teórico analítico introduce una distinción que no desecha lo que Freud afirmó respecto de la temática solo para después ir generalizando la relevancia de la idea novedosa (Mitchell, 1993; Sassenfeld, 2019a). Ello ocurrió a mi parecer con el concepto de los sueños del estado del self; en la actualidad, en el marco del ya mencionado derrumbe de la diferencia entre contenido manifiesto y latente, todos los sueños pueden ser entendidos como sueños del estado del self (para un importante argumento contrario, véase Tolpin, 1983)2. Ello en ningún caso significa que en muchos sueños no se vean retratados conflictos del soñante, sino más bien que hasta la presencia de un conflicto en un sueño da cuenta del estado del self. Con ello, el trabajo de Kohut se encuentra en la tradición de la fenomenología psicoanalítica al tratar el sueño como un fenómeno que se muestra desde sí mismo siendo lo que es y que no está escondiendo su contenido.

Antes de Kohut, en cierto sentido anticipándose a sus ideas, Ronald Fairbairn (1944) había señalado en un sentido más general que todos los sueños se asemejan a cortos cinematográficos que representan de modo condensado la narrativa del self. En otras palabras, para Fairbairn los sueños retratan de modo directo el mundo interno del soñante, que en su conceptualización es un mundo conformado por relaciones objetales internalizadas. Desde esa perspectiva, clínicamente la dimensión central del trabajo analítico con un sueño estaría dado por prestar atención a cómo el yo onírico se relaciona consigo mismo, con los demás y con el mundo, una definición que no podría encajar mejor con los supuestos basales del psicoanálisis relacional. En paralelo a Fairbairn, Jung (1945) destacó lo que denomina la estructura dramática de la mayoría de los sueños. Los sueños son experimentados como historias, en las cuales existe un "escenario" inicial, una situación de partida, un desarrollo, un clímax y finalmente algún tipo de desenlace -incluso a veces la ausencia 
de un desenlace. También para Jung el "drama" representado en un sueño debe ser visualizado como expresión condensada del mundo interno del soñante, lo que Jung describe con su concepto del complejo de tonalidad afectiva. En otras palabras, un sueño representa de forma dramática la estructura de uno o más complejos, que constituyen la subjetividad de acuerdo a la psicología analítica creada por Jung.

Lo que hemos descrito en este punto refuerza la idea mencionada en el punto anterior de que un sueño es un retrato espontáneo del estado de la subjetividad del soñante. Se trata además de un retrato relacional, esto es, de una representación de formas en las que el soñante interna y/o externamente se ha relacionado, se relaciona o se podría llegar a relacionar consigo mismo, con los demás y con el mundo. Considero que en esta idea se expresa la concepción psicoanalítica relacional de los sueños con mayor claridad. Es una idea que abordaremos con mayor detalle en el punto subsiguiente. Por ahora, resumamos que la concepción relacional de los sueños (1) busca ser fenomenológica, con lo que (2) entiende el sueño como un fenómeno y como una experiencia, y (3) colapsa la distinción freudiana entre contenido manifiesto y contenido latente dejando el sueño tal como es. Dicho sea de paso, antes de que Orange (2011) distinguiera la hermenéutica de la sospecha y la hermenéutica de la confianza, Ricoeur (1965) había diferenciado entre la hermenéutica de la sospecha y la hermenéutica de restauración de sentido. Escribió poco acerca de la segunda, pero aquí puede ser atingente mencionar que para él se trataba de una hermenéutica que no enfrenta significados ocultos, sino una saturación de significados. Por ejemplo, cuando se enfrente la Biblia en términos hermenéuticos, no partimos del supuesto de que la Biblia está escondiendo significados; más bien, asumimos que requiere de interpretación porque está saturada de significados. Aunque este no es un aspecto fundamental explícito de la hermenéutica de la confianza delineada por Orange, creo que sí ayuda a clarificar la concepción relacional de los sueños. Los sueños están siempre saturados de significados y eso implica que su interpretación no se agota. En esta afirmación puede reconocerse la impronta de la hermenéutica gadameriana.

(III) En un marco post-kohutiano relacional, Fosshage (1983, 1988, 1989, 1997, 2007, 2013) ha sido tal vez el teórico relacional que con mayor sistematicidad ha dedicado atención a la temática de los sueños desde los mismos inicios del movimiento psicoanalítico relacional. En primer lugar, subraya que el psicoanálisis clásico visualiza los sueños como productos de "una regresión a una modalidad infantil de pensamiento llamada proceso primario, en la cual las pulsiones se descargan por medio de la satisfacción alucinatoria de un deseo" (1983, p. 642). Al surgir de lo inconsciente, dominado por el proceso primario, el sueño no podía participar del pensamiento de proceso secundario más maduro. Este punto de vista se complejizó cuando Freud (1923) articula la teoría estructural del aparato psíquico, pero en esencia permaneció casi igual. En palabras de Fosshage: 
Mi tesis es que esta concepción metapsicológica de los sueños como predominantemente productos de una regresión a niveles primitivos-infantiles de funcionamiento y organización ha tendido a impedir el reconocimiento de los propósitos organizadores o sintetizadores del sueño, la manifestación de niveles variables de organización en los sueños y el uso de los sueños para la evaluación del desarrollo de las relaciones objetales o el nivel de diferenciación y estructuralización de las representaciones del self y del objeto. (pp. 644-645)

Vale decir, Fosshage argumenta que la naturaleza de los procesos oníricos no es ni primitiva ni infantil, sino que sigue una lógica propia que es esencialmente constructiva. Demás está decir que la distinción entre proceso primario y proceso secundario tal como fue delineada por Freud (1911), al igual que la distinción entre contenido manifiesto y contenido latente (véase el primer punto), está profundamente inscrita en la teoría pulsional tradicional.

Frente a este trasfondo general, Fosshage $(1983,1988,1989,1997,2007,2013)$ ha tenido un interés especial en comprender las funciones psicológicas que cumplen los sueños más allá de la idea freudiana de que cumplen la función de una descarga pulsional y de que, al estar disfrazado el deseo pulsional debido a su conflictividad, protegen el dormir del individuo. Proviniendo de la psicología del self, para Fosshage es importante destacar la función psíquica organizadora, integradora y sintetizadora de los sueños. En un denso resumen asevera que "la función superordinada de los sueños es el desarrollo, la mantención (regulación) y, cuando es necesario, la restauración de los procesos, la estructura y la organización psíquicos" (1983, p. 657, cursiva del original), que Stolorow y Atwood (1992) describen como conformada por principios organizadores de la experiencia. Los sueños cumplen esta función básica de tres maneras complementarias: (1) participan en el desarrollo de la organización psíquica a través de la consolidación representacional de configuraciones psíquicas emergentes, un aspecto que sin duda puede vincularse con la concepción neurocientífica de que los sueños contribuyen a consolidar la memoria; (2) los sueños mantienen, regulan y restauran configuraciones psíquicas existentes incluyendo la auto-estima y los impulsos sexuales y agresivos; (3) los sueños dan continuidad a los esfuerzos conscientes e inconscientes despiertos por resolver conflictos psíquicos a través de la utilización de procesos defensivos, del equilibramiento interno o de reorganizaciones creativas emergentes.

En total, el sueño tiene un doble propósito: la mantención de la organización psíquica existente y el desarrollo de nuevas configuraciones psíquicas (Fosshage, 1983, 1988, 1989, 1997, 2007). El segundo propósito mencionado por Fosshage se encuentra en plena congruencia con la existencia de una motivación basal en el ser humano hacia su crecimiento y desarrollo planteada históricamente por Carl Jung, Donald Winnicott, Heinz Kohut, Karen Horney y otros, y más recientemente por Christopher Bollas (1989). Ahora bien, Fosshage (1983) piensa que el hecho de que soñamos mientras dormimos es en sí mismo de relevancia: 
Con una atención y una necesidad reducidas de manejar el mundo externo, el dormir parece ser un momento en el cual el organismo monitorea y regula mediante el proceso de soñar, un estado alterado de consciencia, primaria pero de ninguna manera exclusivamente por medio del uso de la ideación representacional los afectos y pensamientos activados del día, que están entretejidos de modo intrincado con la red representacional de la motivación, la memoria y las representaciones del self y del objeto. La exigencia reducida de lidiar directamente con el mundo exterior proporciona al organismo un tiempo necesario y potente para el desarrollo, la mantención y la restauración de la organización interior. (p. 659)

El dormir da a la psique tiempo y espacio para no tener que lidiar con el mundo externo y poder lidiar en vez de ello consigo misma y sus necesidades.

En este sentido, junto al trabajo de Fosshage, la concepción relacional de los sueños puede visualizarlos como una modalidad extremadamente compleja de los procesos psíquicos que no es de forma primaria primitiva o infantil. Cumplen funciones fundamentales de organización y reorganización de la subjetividad. Al desmantelar las distinciones entre proceso primario y secundario y entre contenido manifiesto y latente en relación con los sueños, las contribuciones de Fosshage (1983) nos permiten "quedarnos con y comprender la imaginería onírica conmovedora en el nivel fenomenológico" (p. 661) cuando trabajamos clínicamente. En vez de contenido manifiesto y latente se limita en términos fenomenológicos a hablar del contenido del sueño (Fosshage, 1983, 1997, 2007), que "del modo más directo revela las preocupaciones del soñante mediante afectos, metáforas y temáticas" (1997, p. 442) sin que ello implique que los significados de un sueño sean transparentes. En otras palabras, aunque el contenido de un sueño no está disfrazado, sus significados a menudo son de todos modos elusivos y difíciles de entender. A ello contribuye una variedad de factores, incluyendo el recuerdo pobre o incompleto del sueño, la falta de claridad de las imágenes oníricas en sí misma, su naturaleza metafórica, la dificultad de comprender material onírico desde el punto de vista de la consciencia despierta o de encontrar sentido al yuxtaponer dos tipos completamente diferentes de procesos psíquicos, o un contexto intersubjetivo y afectivo no facilitador de la exploración de la subjetividad en el seno del cual un sueño es relatado y examinado. Sin embargo, según Fosshage es necesario asumir que las imágenes oníricas presentes en un sueño específico son el mejor lenguaje simbólico disponible al soñante en ese momento para expresar lo que ocurre en la mente inconsciente del soñante.

Los sueños tienen que ser analizados clínicamente en términos de lo que revelan de forma temática y metafórica, no en términos de lo que ocultan. Así, la perspectiva de Fosshage sobre los sueños forma clara parte del giro fenomenológico del psicoanálisis que describí hace poco (Sassenfeld, 2019a). En la práctica clínica, las imágenes oníricas deben entenderse como "representaciones conmovedoramente significativas que sirven como puntos nodales temáticos u organizacionales" (1988, p. 165) y la tarea analítica esencial no es ya la traducción de las 
imágenes oníricas manifiestas a su contenido latente, sino más bien la amplificación y elucidación de los significados que las imágenes oníricas tienen para el paciente. Al abordar un sueño de manera fenomenológica, siguiendo a Fosshage nunca se asume de antemano que el sueño por necesidad tiene un significado transferencial aunque esa posibilidad tampoco se excluye; es una entre diversas posibilidades plausibles y mutuamente no excluyentes. En este sentido, las asociaciones del paciente respecto del sueño se mantienen focalizadas en clarificar las imágenes oníricas en el contexto del mismo sueño y en el contexto de la experiencia que el soñador tuvo dentro del sueño. Mantenerse en el plano fenomenológico tiende a facilitar la participación del paciente en el proceso interpretativo y al mismo tiempo tiende a aumentar la convicción del paciente respecto de los significados elucidados, disminuyendo por otro lado el riesgo de que el psicoterapeuta imponga de forma unilateral y arbitraria sus propias interpretaciones.

Desde el punto de vista del trabajo analítico relacional con sueños en la práctica clínica, Fosshage $(1997,2007)$ parte del supuesto relacional básico de que la interacción psicoterapéutico entre un paciente dado y un psicoterapeuta dado afecta de forma profunda entre otras cosas la disponibilidad de los sueños para el paciente, qué sueños son efectivamente relatados al terapeuta y cómo un sueño es relatado al terapeuta. Asimismo, paciente y psicoterapeuta trabajan en conjunto con el fin de comprender los sueños del paciente, cada uno desde su propia particular e irrepetible subjetividad. Formula algunos principios clínicos básicos para el trabajo analítico con los sueños (esta versión es una síntesis entre las dos versiones que Fosshage presenta en 1997 y 2007): (1) escuchar tan cercanamente como sea posible la experiencia del paciente dentro del sueño; (2) rellenar o completar la experiencia del paciente dentro del sueño a través de preguntas; (3) las imágenes oníricas no necesitan ser traducidas, sino comprendidas en su contenido metafórico y temático; (4) una vez que la experiencia onírica ha sido elaborada, requiere ser vinculada con la vida despierta del paciente; (5) nunca asumir que el contenido de un sueño se relaciona directamente con la transferencia a no ser que el terapeuta aparezca de manera explícita en el sueño o el soñante asocie con el terapeuta; y (6) el trabajo con un sueño puede resultar ser útil en la psicoterapia de cualquier paciente con independencia de la naturaleza de su psicopatología. Por supuesto, en la concepción relacional de los sueños, estos resumidos principios tienen que colocarse en el marco de la phronesis analítica o inteligencia práctica del psicoterapeuta, que guía la toma de decisiones clínicas (véanse Mitchell, 1997; Orange, Atwood \& Stolorow, 1997; Sassenfeld, 2012a, 2016, 2019a, 2019b).

En línea con su aproximación fenomenológica a los sueños, Fosshage (1989) argumenta que ha sido típico en el psicoanálisis que un sueño sea visualizado como un objeto a ser examinado desde la perspectiva de la experiencia despierta. La idea de que un sueño requiere de traducción por parte de una elaboración interpretativa consciente ha introducido en su opinión un sesgo del estado despierto de consciencia que con frecuencia imposibilita la comprensión de la experiencia 
onírica misma. Ello entra en conflicto con lo que le parece la tarea primaria del trabajo analítico con los sueños: "iluminar tanto como sea posible la experiencia del soñante dentro del sueño, no solo la reacción despierta de quien lo relata respecto del sueño [...]" (p. 4, cursiva del original), una idea que reaparecerá en el sexto punto. En conclusión, la

diferencia esencial con el modelo clásico es que yo no considero que las imágenes son seleccionadas con el propósito de disfrazar y, por lo tanto, transformadas en otras imágenes. En cambio, me parece que el soñante selecciona imágenes por su poder evocador y efectiva utilidad en el pensamiento en imágenes, de manera similar a cómo una persona despierta selecciona palabras para promover el proceso de pensar y comunicar. (1997, p. 443)

Para Fosshage, los sueños al igual que los procesos psíquicos despiertos deben visualizarse como procesos organizadores de la subjetividad.

(IV) Las ideas de Jung, Fairbairn y Kohut presentadas en puntos precedentes tienen algo esencial en común: visualizan los sueños como experiencias subjetivas en las que, como en toda experiencia subjetiva, la organización habitual de la subjetividad del soñante o una cierta parte de esta deja su marca inconfundible. Un sueño siempre deja en evidencia algún o algunos aspectos importantes de la organización típica de la experiencia del soñante. En parte, de ahí proviene su tremenda utilidad clínica. George Atwood y Robert Stolorow (2014 [1984]; también, Stolorow \& Atwood, 1982) señalan que históricamente la concepción psicoanalítica de lo inconsciente se desarrolló en conjunto con la interpretación de sueños. Desde ese punto de vista, si la concepción de lo inconsciente sufre transformaciones, es inevitable que ocurra lo mismo con la concepción de los sueños y el trabajo analítico con ellos. Frente al trasfondo de que Stolorow y Atwood (1992) se encuentran entre los teóricos relacionales que con mayor sistematicidad han reformulado la concepción psicoanalítica de lo inconsciente enriqueciéndola en especial con su concepto de un inconsciente pre-reflexivo, resulta lógico asumir que su influyente reformulación no pudo dejar intacta la concepción de los sueños. Escriben:

Argumentamos que una comprensión de la forma de inconsciencia que hemos designado como "pre-reflexiva" arroja nueva luz sobre la importancia única de los sueños para la teoría y práctica psicoanalíticas. Las estructuras pre-reflexivas del mundo subjetivo de una persona son discernibles con la mayor facilidad posible en sus producciones relativamente más sueltas y espontáneas y es probable que no exista otro producto psicológico que sea más suelto y más espontáneo que el sueño. [El] sueño constituye una "via regia" al inconsciente pre-reflexivo -a los principios organizadores y leitmotivs dominantes que de modo inconsciente confieren patrones y tematizan la vida psicológica de una persona. (Atwood \& Stolorow, 2014 [1984], p. 76) 
Por supuesto, el inconsciente pre-reflexivo gira en torno a las estructuras que encauzan la organización habitual de la experiencia subjetiva. Por ende, los sueños "encapsulan el mundo y la historia personales del soñante" (p. 77).

En el marco del proceso analítico, Jung (1995) creía que los sueños, en especial el primer sueño que un paciente relata en su psicoterapia, son tanto diagnósticos como pronósticos (véase Mattoon, 1984) -es decir, pueden desnudar la organización presente de la subjetividad del paciente y a la vez pueden mostrar las posibilidades de un proceso psicoterapéutico y con ello organizaciones alternativas de la subjetividad. Jung fue enfático en rescatar que los fenómenos inconscientes no solo requieren una comprensión retrospectiva que plantea la pregunta por su origen tal como Freud subrayó, sino además una comprensión prospectiva complementaria que plantea la pregunta por su finalidad. La pregunta "¿Por qué?" necesita ser complementada por la pregunta "¿Para qué?", lo que delata el profundo interés de Jung en el desarrollo del individuo englobado en su concepto de individuación (Sassenfeld, 2012C). Este punto de vista guarda una estrecha relación con las anteriormente discutidas actitudes respecto de lo inconsciente; la pregunta respecto del "¿Para qué?" asume con claridad que lo inconsciente no es por definición caótico y amenazante como Freud (1933 [1932]) en ocasiones argumentó, sino que pone de manifiesto cierta direccionalidad propositiva. Galit Atlas y Lewis Aron (2018) están entre quienes han comenzado a rescatar para el psicoanálisis relacional lo que Jung denominó la función prospectiva de los fenómenos inconscientes. En Jung, así como desde mi punto de vista en Heinz Kohut y Donald Winnicott, esa direccionalidad o propositividad está ligada a una "pulsión hacia el destino" (Bollas, 1989), esto es, a lo que promueve el crecimiento del individuo (Sassenfeld, 2012a, 2016, 2019a).

Si un sueño pone de relieve algún aspecto de la organización habitual de la subjetividad del soñante, el análisis del sueño permite al psicoterapeuta en su trabajo conjunto con el paciente sacar ciertas conclusiones respecto de cómo el paciente organiza su propia experiencia. Recordemos que, en un marco psicoanalítico relacional, ser un sujeto significa ser un organizador activo aunque muchas veces inconsciente de la propia experiencia (Orange, 1995; Sassenfeld, 2012a, 2016, 2019a). Es decir, la experiencia no es simplemente algo que a uno le acontece de manera pasiva; tenemos una implicación directa y relevante en cómo nos acontece y afecta. Con ello, un sueño relatado por el paciente siempre trae consigo una gran potencialidad en términos clínicos: un sueño deja en evidencia no tan solo la experiencia del paciente como tal, sino más profundamente la modalidad básica de organización de esta -lo que Atwood y Stolorow (2014 [1984]) Ilaman las estructuras de la subjetividad. Mientras que el paciente tiende a relatar un sueño simplemente como una experiencia que tuvo, el trabajo del psicoterapeuta no se limita a acoger empáticamente esa experiencia, sino que además está ligado a interpretar la forma de organización de la experiencia del paciente. La pregunta por la forma es siempre la pregunta por 
el cómo, por la manera particular en la que el paciente se experimentó a sí mismo, a los demás y al mundo en el sueño. Como sabemos, la organización de la experiencia se produce de modo habitual de manera inconsciente. A ello se debe que alguien consulte a un psicoterapeuta con la esperanza de poder transformar su propia experiencia -conscientizar y cambiar nuestra propia forma de organizar nuestra propia experiencia tiende a requerir a un otro capaz de retroalimentarnos. En consecuencia, gran parte del trabajo analítico guarda relación con elevar la consciencia del paciente respecto de que es un organizador activo de su propia experiencia y de que, por ende, pueden existir modos distintos de organizarla que pudieran generar un sentir diferente y más satisfactorio.

Asumir que la organización habitual de la experiencia de un sujeto queda graficada en sus sueños significa en términos clínicos comenzar a prestar atención sistemática a cómo el yo onírico figura en un sueño. ¿Qué capacidades pone de manifiesto? ¿Qué limitaciones quedan en evidencia? ¿Cómo se comporta? ¿Qué hace y qué no hace? ¿Cómo reacciona frente a las situaciones del sueño y cómo las maneja? Estas interrogantes son fundamentales tanto por si confirman la representación onírica de actitudes efectivas del soñante como por si lo muestran en actitudes distintas a las típicas. Jung (1928) expuso su teoría de la compensación para explicar la relación de lo consciente con lo inconsciente, de acuerdo a la cual las manifestaciones de lo inconsciente tienden a compensar la unilateralidad de la consciencia. En otras palabras, con frecuencia lo inconsciente $-y$, por ende, los sueños- introduce elementos que la consciencia no hubiese considerado o que derechamente se ha negado a tomar en consideración pero que en términos de la totalidad psíquica y su crecimiento tienen su relevancia. Es decir, Jung concibió la psique como un sistema auto-regulatorio en función de su propio crecimiento (Sassenfeld, 2012c). Este punto de vista implica que todo sueño necesita entenderse en relación con la situación consciente del soñante; los sueños se visualizan como referencia directa a la situación en la que se encuentra la consciencia, que puede ser la situación inmediata o bien la situación en un sentido un tanto más amplio. En términos terapéuticos, esto significa que ningún sueño está interpretado suficientemente bien si la interpretación no logra vincular lo soñado con la vida despierta del soñante, idea que ya encontramos en el trabajo de Fosshage. Asumo que esta idea es en la actualidad un principio general; un sueño solo puede ser terapéuticamente útil si su interpretación analítica contribuye a movilizar al paciente de una u otra manera en términos de su vida concreta.

¿En qué nos detenemos como psicoterapeutas cuando analizamos un sueño? Esta pregunta tiene por supuesto una amplia diversidad de respuestas posibles. Basándonos en lo que hemos desarrollado en lo anterior cabe volver a destacar que estamos interesados principalmente en cómo el yo onírico se relaciona dentro del sueño consigo mismo, con otros elementos y personas que figuran en el sueño y con el mundo en general. Nos interesa principalmente dejar en evidencia cómo un sueño pone al descubierto la manera en la que el yo se vincula con los demás elementos del 
sueño. Para mí, esta es la idea más básica en una concepción relacional de los sueños. Nos interesan las relaciones y la forma que estas adoptan en un sueño determinado soñado por un sujeto determinado. Con frecuencia, se trata de relaciones con otras personas, pero también la forma de relación con objetos, animales, espacios y los infinitos elementos que pueden componer un sueño específico son de relevancia porque también allí queda al descubierto la organización de la experiencia del paciente. Retomando lo descrito al comenzar este tercer punto, los sueños proporcionan un acceso muy significativo y directo a lo inconsciente pre-reflexivo, que es la dimensión de lo inconsciente que está conformada por los denominados principios organizadores de la subjetividad (Orange, 1995; Sassenfeld, 2012a, 2012b, 2013, 2014, 2016, 2019a; Stolorow \& Atwood, 1992; Stolorow, Atwood \& Orange, 2002). Orange (1995) los ha definido de manera cercana a la experiencia como convicciones o conclusiones emocionales que el sujeto ha sacado a partir de su experiencia emocional e intersubjetiva respecto de cómo funcionan los vínculos afectivos y que, por ende, terminan siendo la variable central que da forma habitual a su experiencia.

Frente a este trasfondo, Atwood y Stolorow (2014 [1984]) entienden los sueños en base a su idea de que la fuerza motivacional básica del individuo es mantener la organización existente de la experiencia. Así, asumen que los sueños pueden visualizarse como "guardianes de la estructura psicológica [...]" (p. 80, cursiva del original). A su parecer, contribuyen a reforzar los principios existentes de organización de la subjetividad e intentan, cuando la organización habitual de la subjetividad por algún motivo se ve amenazada, resguardarla y/o restablecerla. Esta función de los sueños está emparentada con aquella que muchos neurocientíficos les atribuyen: contribuir a la consolidación de la memoria. Sea como sea, creo haber mostrado en este punto que la concepción relacional de los sueños coloca en un lugar central la relación entre el sueño y la organización típica de la experiencia. Además, así como en un punto anterior destaqué la relevancia del desarrollo desde la hermenéutica de la sospecha característica del psicoanálisis clásico hacia la hermenéutica de la confianza característica del psicoanálisis relacional, en este punto pudimos ver que la transformación de la concepción psicoanalítica de lo inconsciente implica de modo directo cambios en la concepción psicoanalítica de los sueños. Hemos pasado del sueño como realización de un deseo hacia el sueño como experiencia en la que quedan en evidencia las estructuras pre-reflexivas de la subjetividad del soñante.

(V) Afirmé con anterioridad junto a Atwood y Stolorow (2014 [1984]) que cambios en la concepción psicoanalítica de lo inconsciente necesariamente traían consigo cambios en la concepción de los sueños. En este punto, agregaré otro aspecto a esa misma idea tomando en consideración transformaciones importantes en la teoría psicoanalítica de la motivación. El 
psicoanálisis relacional, en buena medida gracias al giro fenomenológico del psicoanálisis contemporáneo (Sassenfeld, 2019a), ha reformulado por completo su teoría motivacional. Dado que el psicoanálisis relacional se ha distanciado de la teoría freudiana de la motivación basada en el concepto de pulsión (Mitchell, 1988), ha tenido que desarrollar una alternativa conceptual para explicar por qué las personas actúan cómo actúan. Los teóricos relacionales más importantes que han dedicado atención a esta temática, influenciados en profundidad por la investigación de infantes, la teoría del apego y las neurociencias afectivas y sociales, coinciden en que el concepto de pulsión ha sido reemplazado por el concepto de afecto (Lichtenberg, Lachmann \& Fosshage, 1992, 1996, 2011; Sassenfeld, 2012a, 2012d, 2016, 2019a; Stolorow, 2002). Vale decir, las personas actúan en base a lo que sienten; lo que no excluye sino que incluye la experiencia de sentirse impulsado a actuar por un impulso -solo que un impulso ya no es retrotraído a una pulsión subyacente, sino que es comprendido en términos fenomenológicos como una experiencia de sentirse impulsado. El cambio de la teoría pulsional a la teoría afectiva de la motivación significa algunas cosas muy concretas: en primer lugar, tal como Stolorow (2002) subraya, a diferencia de una pulsión arraigada en un modelo intrapsíquico de la psique en cuanto mente aislada, los estados emocionales están siempre ya ligados a contextos intersubjetivos en los que estos son regulados -cómo me siento es indesligable de mis relaciones con los otros. Mientras que la pulsión aísla, el afecto contextualiza.

Ahora bien, ¿qué implicancias puede tener la teoría motivacional basada en los afectos en relación con la temática de los sueños? Existe al menos una implicancia fundamental: ahí donde el psicoanálisis clásico busca interpretar el deseo inconsciente que se expresa a través del sueño, el psicoanálisis relacional intenta seguirle la pista a los diferentes afectos que se despliegan en la experiencia onírica. Intenta explorar, articular y transformar mundos subjetivos de experiencia (Stolorow, Atwood \& Orange, 2002; Stolorow, Brandchaft \& Atwood, 1987), debido a lo cual se esfuerza por mantenerse cercano a la experiencia directa del paciente que está dada por lo común por los afectos. De hecho, uno de los principios clínicos básicos del psicoanálisis relacional dicta no solo permanecer cerca de la experiencia afectiva, sino ir ajustando las intervenciones del terapeuta en función del impacto emocional que van generando en el paciente (Sassenfeld, 2012a; Lichtenberg, Lachmann \& Fosshage, 1996). En otras palabras, un psicoterapeuta relacional busca hacer respecto de la experiencia onírica -una actividad afectiva-cognitiva (Fosshage, 1988)- lo mismo que busca hacer respecto de las experiencias del paciente en general: sintonizar con la dimensión afectiva porque asume que los afectos son tanto la dimensión central de la experiencia humana -por algo el concepto de regulación afectiva se encuentra en el centro del psicoanálisis relacional (Hill, 2015; Sassenfeld, 2019 [2006], 2012a, 2016, 2019a; Schore, 2003a, 2003b, 2012, 2019a, 2019b)- como la via regia hacia las posibilidades del cambio analítico. Recordemos en este sentido, por ejemplo, que Orange (1995) hace ya más de veinte años indicó la necesidad de que el 
insight analítico tradicional se convirtiera en el trabajo conjunto de paciente y psicoterapeuta por alcanzar una comprensión emocional co-construida.

En términos prácticos, lo dicho quiere decir que, cuando trabajamos clínicamente con un sueño, la afectividad se encuentra siempre en un primer plano. El contenido fáctico de un sueño en cuanto experiencia subjetiva es evidentemente fundamental; sin embargo, en el sentido terapéutico es aún más relevante recoger los afectos presentes en la experiencia onírica así como las secuencias emocionales que quedan en evidencia y, por otro lado, no perder de vista que los mismos sueños cumplen funciones de regulación afectiva (Fosshage, 2007, 2013). La afectividad presente en un sueño es por supuesto un aspecto fundamental de la organización de la subjetividad del soñante: es, en efecto, la dimensión más concreta y vivencial de un sueño -y, a menudo, de las consecuencias de haber soñado- y por lo demás la afectividad siempre guarda relación con la situación consciente del soñante, aunque este no sea capaz de entenderla como tal. Lo que ocurre afectivamente entre el yo onírico y otros elementos del sueño es una dimensión central de la organización de la subjetividad del paciente. El afecto es, efectivamente, una especie de pegamento que mantiene unidos los diferentes y diversos elementos que constituyen un sueño, tal como ocurre con toda experiencia. En consecuencia, el trabajo analítico con un sueño tiene que enfocarse en la afectividad como dimensión basal del self que deja al descubierto la organización de la subjetividad del soñante en la imaginería onírica. Desde el punto de vista relacional, abordar un sueño en términos clínicos equivale siempre a elaborar la afectividad presente en un sueño. Soñar y sentir son, por razones obvias, dimensiones inseparables en la experiencia de la mayor parte de nuestros pacientes.

(VI) Otro de los teóricos relacionales que ha hecho referencia de forma relativamente sistemática a los sueños es Bromberg $(1998,2006,2011)$. En términos generales, para Bromberg un sueño se debe entender como el caso más familiar del fenómeno de la disociación, "la capacidad autohipnótica normal de la mente humana [...]" (1998, pp. 297-298). Recordemos que el psicoanálisis relacional concibe en términos generales la psique como una mente disociativa por naturaleza (Howell, 2005; Howell \& Itzkowitz, 2016; Sassenfeld, 2012a, 2019a; Stern, 1997, 2010, 2015). Bromberg cree que el sueño, en cuanto proceso nocturno habitual de la disociación, representa "un esfuerzo adaptativo de lidiar con niveles mínimos de la experiencia no-yo sin interferir con la ilusión despierta de una consciencia central" (p. 298). Prosigue:

Una de sus manifestaciones en el psicoanálisis es contener y sostener, como realidad separada, experiencia no procesada que no está seguramente contenida en ese momento dentro del "yo" que define la relación analítica para el paciente [...] En otras palabras, el uso de un sueño en el análisis puede en un nivel visualizarse como una experiencia transicional que permite la vinculación potencial de estados del self que están desconectados hipnoidemente, 
permitiendo que se escuchen las voces de estados del self "no-yo" y que encuentren acceso a la estructura dinámica que el paciente define como "yo". (p. 298)

La conceptualización de Bromberg inscribe el sueño en el dominio de los fenómenos disociativos $y$, con ello, se encuentra entre los teóricos analíticos que le atribuyen una función de procesamiento de experiencias y sentimientos traumáticamente disociados así como convierte el trabajo con un sueño en una poderosa herramienta clínica para acceder a lo disociado.

Para poder entender bien lo recién dicho por Bromberg pueden ser necesarios algunos comentarios aclaratorios. En su conceptualización, la subjetividad está conformado por múltiples estados del self, algunos de los cuales le resultan aceptables a la consciencia y por ende pertenecen a la categoría del "yo" ( $m e$ ) mientras que otros son percibidos como amenazantes para la consciencia y por ende permanecen defensivamente disociados en la categoría del "no-yo" (not$m e$ ). El origen de los estados del self que conforman el no-yo debe buscarse en el desarrollo temprano; allí, tales estados del self del niño recibieron algún tipo de respuesta de invalidación y desconfirmación (p. ej., omisión, rechazo activo, rechazo pasivo, temor, angustia, etc.) por parte del los cuidadores y en consecuencia fueron percibidos como amenazas a la necesitada relación con los cuidadores. Tal percepción dio lugar a la actuación de procesos disociativos defensivos que convirtieron ciertos estados del self en no-yo. Todo lo descrito constituye el núcleo del trauma relacional que, para Bromberg, en diversa medida contribuye a estructurar la subjetividad de todos los seres humanos. Frente a este trasfondo, entonces, su concepción del sueño significa que este debe visualizarse como intento psíquico por acercar estados disociados del self a la consciencia y, con ello, por reemplazar la disociación con la vivencia de un conflicto interno entre estados del self anteriormente incapaces de ser contenidos en el mismo espacio psíquico.

La discusión precedente es resumida por Bromberg (2006) de la siguiente manera: "Cuando un paciente trae un sueño, la tarea analítica es capacitarlo para que traiga al soñador" ( $\mathrm{p}$. 38, cursiva del original). Puesto que el "soñador" o "yo onírico" es entendido por Bromberg como un estado del self que está disociado de la consciencia -en este caso, específicamente de la consciencia despierta-, lo más relevante desde el punto de vista del proceso analítico es que el estado del self "soñador" pueda comenzar a participar de la sesión psicoterapéutica más allá de ser un mero personaje en una historia soñada. Bromberg señala:

Retrataría el proceso [de elaborar un sueño] como un desarrollo gradual de un diálogo entre el estado despierto del self del paciente-como-paciente y el estado dormido del self del pacientecomo-soñador [...] Al implicarse con todos los estados del self del paciente en relaciones que son afectivamente responsivas a cada uno en sus propios términos, el analista descubre en detalle todas las realidades del paciente, permitiéndole al paciente con ello experimentar "quién es" con un sentido de claridad y autenticidad personal. (p. 39, cursiva del original) 
Bromberg asevera que muchos psicoterapeutas se coluden con la experiencia despierta que el paciente tiene de su sueño como algo vivencialmente ajeno que puede ser conocido solo de modo indirecto en cuanto sueño recordado. En contraste con ello, en términos clínicos Bromberg busca más bien aprovechar la capacidad del paciente "de volver a entrar en su propio espacio onírico reteniendo de manera simultánea su realidad despierta [...]" (p. 40, cursiva del original).

Bromberg (2006) destaca que, en presencia de un otro (el terapeuta) involucrado afectivamente de forma apropiada, la mayor parte de las personas dispone de la capacidad experiencial mencionada, que guarda relación con la experiencia del espacio transicional descrito por Winnicott (1953). La presencia de un otro responsivo es central ya que, si en el sueño surgen estados disociados del self que el yo percibe como no-yo, solo un otro capaz de no volver a desconfirmar la realidad de tales estados del self o de sentirse amenazado por estos puede posibilitar el diálogo efectivo entre yo y no-yo. Bromberg clarifica que no aboga por el uso de la inducción técnica concreta de un trance hipnótico, similar a una parte del trabajo prepsicoanalítico de Freud. Más bien, aboga por "una invitación al paciente-como-paciente de 'hacer entrar al soñador' -una invitación que, debido a que esta misma es objeto de negociación intersubjetiva [entre paciente y analista], mejora más que invade el flujo natural del proceso relacional analítico" (p. 41, cursiva del original). Más allá, siguiendo a Bromberg los sueños no representan una via regia privilegiada de acceso a lo inconsciente en comparación, por ejemplo, con las ensoñaciones diurnas dado que estas con frecuencia tienen mayor inmediatez y permiten al paciente hacer un uso lúdico de su imaginación. Así, "podría argumentarse que, en mi propia forma de trabajar, intento convertir sueños nocturnos en ensoñaciones diurnas" (p. 42) en las cuales el paciente puede implicarse de manera activa e inmediata.

A Bromberg (2006) le parece fundamental asumir que el trabajo analítico con un sueño no guarda relación con esforzarse por visualizarlo como una narrativa a ser comprendida en términos interpretativos, sino como una realidad a ser experimentada con tanto detalle como sea posible como si estuviera ocurriendo en el presente de la sesión psicoterapéutica. "Así, hago el intento de preguntar por detalles de la manera que más le ayude al paciente a entrar en el sueño como una experiencia corporal aquí-y-ahora" (p. 42), preguntando en este sentido en la modalidad del presente: no "¿Cómo era ese hombre que viste correr?", sino "¿Cómo es ese hombre que ves correr?". Su aproximación guarda claros paralelos con la manera en la que muchos psicoterapeutas jungianos y gestálticos trabajan clínicamente con sueños. "La idea es capacitar al paciente para adentrarse más y más en el espacio onírico y no simplemente permanecer en el texto onírico" (p. 43, cursivas del original). Bromberg considera que, mientras el paciente se sumerge más y más en la experiencia corporal y afectiva del sueño en el presente de la sesión analítica, el estado del self "soñador" comienza a emerger en la sesión de modo habitual a través de la aparición de una escenificación 3 . Por lo tanto, el trabajo clínico con un sueño termina por lo común 
siendo a la vez trabajo clínico en torno a la interacción entre paciente y psicoterapeuta. Bromberg señala que

cuando un sueño es relatado y gradualmente re-experimentado en términos subjetivos aquellos aspectos que representan experiencia no procesada de la vida real (muchas veces experiencias no simbolizadas del análisis mismo) serán escenificados en la relación pacienteanalista, como toda experiencia no procesada de alta significación afectiva. En otras palabras, el analista no es simplemente un guía que acompaña al paciente en su viaje por la via regia; es un participante en la construcción de la vía y, esperamos, en la reparación de sus baches. (pp. 43-44, cursiva del original)

El trabajo de Bromberg nos muestra que la concepción relacional de los sueños enfatiza la estrecha relación entre sueño, trabajo terapéutico con el sueño y vínculo psicoterapéutico. En ocasiones, de hecho, me he preguntado si no existen acaso sueños que más que productos del inconsciente del paciente o del psicoterapeuta son más bien productos de lo inconsciente relacional (Gerson, 2004; Sassenfeld, 2012a, 2019a; Zeddies, 2000). Esta idea quedará por ahora sin ser desarrollada aquí. Solo quisiera añadir que en una carta del año 1934, Jung escribió hace mucho tiempo que en "el sentido más profundo, todos no soñamos desde nosotros, sino desde aquello que se encuentra entre nosotros y el otro" (cursivas del original), aseveración que se asemeja a la idea de que pudieran existir sueños que surgen desde el entre paciente y terapeuta y cuya autoría por ende se convertiría en una interrogante interesante. Por otro lado, las formulaciones de Bromberg dejan en evidencia la versatilidad práctica que los psicoterapeutas relacionales pueden llegar a emplear en su trabajo clínico, versatilidad alejada del psicoanálisis clásico tanto por su fundamentación teórica como por la forma concreta que adopta. De modo similar pero distinto a lo que afirmé al discutir las ideas de Stolorow y Atwood respecto de los sueños, la concepción de Bromberg liga el sueño con una cierta dimensión de lo inconsciente: el sueño es expresión del inconsciente disociado y acerca tentativamente a la consciencia elementos inconscientes defensivamente excluidos de la consciencia para su integración.

(VII) En una concepción relacional de los sueños, en el marco del giro hermenéutico del psicoanálisis contemporáneo (Sassenfeld, 2019a), estos por definición se entienden como polisémicos, esto es, siempre portan múltiples significados de manera simultánea. No existe el significado de un sueño; los sueños más bien son siempre condensaciones de significación, debido a lo cual tienden a no agotarse. Muchos psicoterapeutas probablemente reconozcan la experiencia de que en ciertos procesos analíticos se retorna de forma repetida a un mismo sueño que parece continuar ofreciendo significados relevantes. Más en general, la mayor parte de las personas recuerdan ciertos sueños que han tenido a lo largo de su vida sin que hayan perdido su carga emocional significativa. Es decir, algunas experiencias oníricas se asemejan a ciertas experiencias 
despiertas muy importantes que se graban en nuestra memoria de manera duradera. En ese contexto, ¿qué significa interpretar un sueño desde la perspectiva del psicoanálisis relacional? En mi libro El espacio hermenéutico (2016) dediqué considerable atención a explorar los conceptos de comprensión e interpretación desde un punto de vista analítico hermenéutico. Una idea central es que la interpretación, como proceso facilitador de la comprensión, procede mediante la contextualización del objeto que es interpretado. En otras palabras, contextualizar lo que buscamos comprender efectivamente promueve de forma gradual y progresiva nuestra comprensión. Así, nuestro trabajo al interpretar un sueño es "generar contextos de significado subjetivo en términos de los cuales la imaginería onírica pueda ser examinada y entendida" (Atwood \& Stolorow, 2014 [1984], p. 77, cursiva del original).

El psicoanálisis clásico tendió a reducir muchísimo las posibilidades de contextualización de un sueño. Por un lado, el contexto principal siempre fue el deseo inconsciente conflictivo que se manifiesta en el contenido latente del sueño (contexto además reducido aún más al solo enfocar deseos ligados al complejo de Edipo) y, por otro lado, un contexto adicional mucho menos relevante y constructivo en términos de la comprensión de un sueño fue lo que Freud (1900) llamó los restos diurnos, esto es, aspectos de la experiencia del día previo al sueño que encontraron de una $u$ otra manera entrada en su trama. También siempre fue un contexto importante la transferencia del paciente hacia el psicoanalista, asumiéndose a veces que por necesidad todos los sueños tienen significados transferenciales que deben ser interpretados. Así, la hermenéutica psicoanalítica clásica con frecuencia se convierte en una hermenéutica tautológica y que se reafirma a sí misma: por lo común, encuentra los significados que busca en función de sus propios supuestos teóricos y, además, el espectro de posibles significados es increíblemente estrecho y reiterativo. Los puntos anteriores que ya hemos explorado en este trabajo sobre la concepción relacional de los sueños dejan en evidencia que para el psicoanálisis relacional los contextos de significado subjetivo que facilitan la comprensión interpretativa de un sueño son mucho más amplios, diversos y numerosos.

Los contextos de significado subjetivo que facilitan la comprensión de un sueño pueden y de hecho incluyen los contextos recién mencionados que son destacados por el psicoanálisis clásico, pero abarcan también un sinnúmero de contextos adicionales como el desarrollo temprano del paciente, aspectos transgeneracionales de la historia familiar del paciente, las experiencias traumáticas que atravesó, los aspectos defensivamente disociados de su experiencia, las estructuras pre-reflexivas de la experiencia, los distintos estados del self que constituyen su subjetividad y las relaciones existentes entre estos, el momento vital del paciente y las tareas y desafíos que trae consigo, su presente inmediato, contextos sociales, culturales, lingüísticos e históricos de diversa índole, la interacción analítica no transferencial, la interacción analítica noverbal implícita, el momento del proceso analítico y el proceso analítico en su globalidad, etc. 
Diferentes contextos posibilitan contemplar un sueño desde distintos puntos de vista y, con ello, enriquecen enormemente las posibilidades del trabajo clínico con los significados oníricos. Respecto de qué contextos resultarán ser útiles y relevantes en un momento dado con un determinado sueño de un paciente dado en un determinado momento de su proceso psicoterapéutico no pueden establecerse reglas; recuérdese que, en cuanto práctica hermenéutica, el psicoanálisis relacional se ha ido alejando cada vez más del concepto de una técnica estandarizable y ha subrayado la noción de la phronesis analítica, es decir, la forma en la que en realidad funciona la mente del psicoterapeuta cuando este se encuentra junto a un paciente (Mitchell, 1997; Orange, Atwood \& Stolorow, 1997; Sassenfeld, 2012a, 2016, 2019a, 2019b).

Mi trabajo en El espacio hermenéutico (2016) tuvo relación entre otras cosas con volver la hermenéutica psicoanalítica relacional consciente de sus propias posibilidades y limitaciones. Parte de ese proyecto estuvo ligado a comprender el concepto de interpretación. En español, solo contamos con la palabra interpretación; en alemán, en cambio, idioma utilizado por los principales teóricos de la hermenéutica y por supuesto también por Freud, existen al menos tres palabras con sutiles matices para dar cuenta del concepto de interpretación. En primer lugar, existe el concepto de Interpretation, que se traduce directamente como interpretación. Este primer aspecto no es de gran interés; lo son, más bien, las otras dos palabras que en alemán se relacionan con la idea de interpretación. Se trata de los términos Deutung y Auslegung. De modo significativo, La interpretación de los sueños (1900) de Freud ocupa en su título la palabra Deutung, entendida eso sí como trabajo que el analista tiene que llevar a cabo en su interior y solo con posterioridad comunicarle al paciente el resultado final. Para los teóricos hermenéuticos, Deutung es un término que hace referencia a una interpretación global de algo. En relación con los sueños, la Deutung de un sueño se vincula con el esfuerzo por darle un significado a un sueño en su totalidad con relativa independencia de todos los innumerables detalles que un sueño siempre incluye. Se trata del trabajo de interpretar el sentido general de un sueño. Muchos psicoterapeutas apuntan en sus esfuerzos interpretativos a este aspecto, Freud siendo el primero de ellos. Contemplar un sueño como totalidad no deja de ser una capacidad significativa; dependiendo de la forma particular de nuestra subjetividad, los psicoterapeutas tenemos más o menos facilidad para percibir esa totalidad de significado. En la psicología jungiana, esa facilidad se relaciona de cerca con el desarrollo de la función psíquica de la intuición, que el mismo Jung tenía altamente desarrollada. Debido a ello, a Jung le resultaba fácil captar el sentido general de los sueños de sus pacientes.

Quienes sienten que no cuentan con esa facilidad pueden quizás estar agradecidos de que también existe (en alemán) la modalidad de interpretación de la Auslegung de un sueño. En términos simples, Auslegung quiere literalmente decir des-componer un sueño, similar al significado del término analizar. Se trata, entonces, de examinar los diferentes aspectos 
relevantes de un sueño por separado observando en qué dirección cada uno lleva en la exploración conjunta entre paciente y psicoterapeuta. Esta modalidad del trabajo interpretativo con cierta facilidad puede alejarnos del sueño mismo y contactarnos con alguna temática importante en la subjetividad e historia del paciente. A veces, la aparición de esa temática amerita que dejemos por el momento el sueño de lado y profundicemos en lo que ha emergido. Jung era muy consciente de esta posibilidad y, en consecuencia, tendía a comentar al paciente, "Muy bien, ahora volvamos al sueño", cuando el sueño en cuestión había dejado de ser el objeto principal de la atención analítica. Como hemos visto, es probable que teóricos relacionales como Fosshage y Bromberg con su énfasis sistemático en permanecer en la experiencia onírica se mostrarían de acuerdo con la estrategia de Jung. Ahora bien, Deutung y Auslegung no deben en ningún caso visualizarse como dos modalidades interpretativas mutuamente excluyentes; muy por el contrario son complementarias. Es frecuente que a un trabajo de Auslegung siga la formulación de una Deutung. Se trata de dos formas distintas de acceder a los significados del sueño; solo que una Auslegung bien manejada tiende a arrojar varios significados oníricos, mientras que la Deutung tiende a focalizarse en un significado en particular capaz de englobar la complejidad de un sueño.

No cabe duda de que la hermenéutica filosófica, especialmente aquella articulada por Gadamer, tiene mucho que aportar a la concepción relacional de los sueños. En este contexto, me he limitado a dar cuenta de algunos pocos elementos: los sueños como fuente de múltiples significados, el proceso interpretativo como un proceso intersubjetivo dialógico al que contribuyen tanto paciente como terapeuta, y la existencia de distintas modalidades de interpretación. En el primer punto además discutí el contraste entre hermenéutica de la sospecha y hermenéutica de la confianza, y subrayé que solo la hermenéutica intersubjetiva de la confianza se encuentra en consonancia con los principios básicos del psicoanálisis relacional. El giro hermenéutico en el psicoanálisis contemporáneo implica que, cuando paciente y psicoterapeuta se encuentran frente a un sueño, solo una conversación genuina entre ambos será capaz de desentrañar algunos de los significados del sueño. La máxima hermenéutica de Gadamer, "El otro puede tener razón", puede aquí ser complementada con lo que Jung se decía a sí mismo siempre antes de enfrentar la interpretación de un sueño: "No tengo idea de lo que significa este sueño", como en un esfuerzo por abrirse a la experiencia dialógica de elaborar el sueño. A mi parecer, los teóricos relacionales aún tenemos mucho que aprender de la hermenéutica y no solo en relación con la interpretación de los sueños (Sassenfeld, 2010a, 2012a, 2016, 2019a).

Espero haber logrado en estas notas pasar revista a algunos de los aspectos más relevantes de la concepción psicoanalítica relacional de los sueños. Tal como mencioné en el inicio de este trabajo, en mi opinión aún son pocas las contribuciones relacionales a la comprensión de los sueños y a su abordaje psicoterapéutico. Quedan muchos aspectos por explorar desde la perspectiva relacional en lo que atañe a los sueños. Como pudimos comprobar, los teóricos relacionales consideran que 
si han cambiado las ideas psicoanalíticas respecto de lo inconsciente y la motivación, ello no puede más que afectar la forma en la que entendemos y en la que abordamos clínicamente los sueños. Creo que apenas hemos comenzado a explicitar estos cambios y, aquí, hemos podido ver que el giro fenomenológico y el giro hermenéutico han transformado no solo el psicoanálisis en términos generales, sino a la vez su concepción de los sueños en particular. Al colapsar la distinción entre contenido latente y contenido manifiesto introducida tempranamente por Freud (1900), ha pasado a un primer plano la experiencia que el paciente tiene de un sueño y la comprensión del sueño como un fenómeno que se muestra desde sí mismo como aquello que es sin disfrazar ni ocultar nada. Las dificultades que podamos experimentar a la hora de interpretar los sueños hablan más de nuestra incapacidad para entender el lenguaje que el sueño ocupa que de su supuesto intento de no revelar sus significados.

Hay una serie de temáticas atingentes que quedaron en este trabajo sin ser tocadas: los sueños del psicoterapeuta en los que aparece alguno de sus pacientes, el hecho de que el paciente traiga sueños a sus sesiones terapéuticas como posible complacencia, los sueños repetitivos, las pesadillas, los frecuentes paralelos simbólicos de las imágenes oníricas con otros tipos de experiencias simbólicas, y muchos otros más. No era aquí ni posible ni mi objetivo abarcar todos estos aspectos, sino limitarme a elementos fundamentales de la concepción relacional de los sueños. Asimismo, espero haber podido, tal como anuncié en la introducción, contribuir a convertir a Jung en uno de los ancestros del psicoanálisis relacional que aún ha recibido poca atención. Sus escritos sobre sueños son fuente de originales y útiles ideas sobre la labor analítica con los sueños. Tan solo algunas de esas ideas pudieron ser mencionadas en este trabajo. Después de milenios de historia documentada de la humanidad, los sueños siguen siendo experiencias humanas que nos intrigan e impactan, y no solo a los psicoterapeutas. En su pretensión de comprender al ser humano más que a Freud (Kohut, 1982), el psicoanálisis contemporáneo necesita a mi parecer seguir haciendo esfuerzos por prestar atención a tales experiencias. Después de todo, y en eso los teóricos relacionales siguen alineados con Freud, los sueños son una de nuestras vías más inmediatas de percepción de lo inconsciente.

\section{REFERENCIAS}

Atlas, G. \& Aron, L. (2018). Dramatic Dialogue: Contemporary Clinical Practice. New York: Routledge.

Atwood, G. \& Stolorow, R. (2014 [1984]). Structures of Subjectivity: Explorations in Psychoanalytic Phenomenology and Contextualism (2. Ed.). New York: Routledge.

Beebe, J. (1997). Attitudes toward the unconscious. Journal of Analytical Psychology, 42, 3-20.

Blechner, M. (2001). The Dream Frontier. New Jersey: The Analytic Press. 
Blechner, M. (2018). The Mindbrain and Dreams: An Exploration of Dreaming, Thinking, and Artistic Creation. New York: Routledge.

Bollas, C. (1989). The destiny drive. En C. Bollas, The Christopher Bollas Reader (pp. 37-56). New York: Routledge.

Bromberg, P. (1998). Standing in the Spaces: Essays on Clinical Process, Trauma, and Dissociation. New York: Psychology Press.

Bromberg, P. (2006). Awakening the Dreamer: Clinical Journeys. New Jersey: The Analytic Press.

Bromberg, P. (2011). The Shadow of the Tsunami and the Growth of the Relational Mind. New York: Routledge.

Buirski, P. \& Haglund, P. (2001). Making Sense Together: The Intersubjective Approach to Psychotherapy. New Jersey: Jason Aronson.

Damasio, A. (2010). Y el cerebro creó al hombre. Barcelona: Ediciones Destino.

Fairbairn, W. R. (1944). Endopsychic structure considered in terms of object-relationships. En W. R. Fairbairn, Psychoanalytical Studies of the Personality. New York: Routledge.

Fosshage, J. (1983). The psychological function of dreams: A revised psychoanalytic perspective. Psychoanalysis and Contemporary Thought, 6 (4), 641-669.

Fosshage, J. (1988). Dream interpretation revisited. En A. Goldberg (Ed.), Progress in Self Psychology: Frontiers in Self Psychology (Vol. 3) (pp. 161-175). New Jersey: The Analytic Press.

Fosshage, J. (1989). The developmental function of dreaming mentation: Clinical implications. En A. Goldberg (Ed.), Progress in Self Psychology (Vol. 5) (pp. 3-11). New Jersey: The Analytic Press.

Fosshage, J. (1997). The organizing function of dream mentation. Contemporary Psychoanalysis, 33 (3), 429-458.

Fosshage, J. (2007). The organizing function of dreaming: Pivotal issues in understanding and working with dreams. International Forum of Psychoanalysis, 16, 213-221.

Fosshage, J. (2013). The dream narrative: Unconscious organizing activity in context. Contemporary Psychoanalysis, 49 (2), 253-258.

Freud, S. (1900). Die Traumdeutung. Frankfurt am Main: S. Fischer Verlag.

Freud, S. (1911). Formulaciones sobre los dos principios del acaecer psíquico. En S. Freud, Obras Completas (XII) (pp. 217-232). Buenos Aires: Amorrortu.

Freud, S. (1923). El yo y el ello. En S. Freud, Obras Completas (XIX) (pp. 1-66). Buenos Aires: Amorrortu.

Freud, S. (1933 [1932]). Nuevas conferencias de introducción al psicoanálisis. En S. Freud, Obras Completas (XXII) (pp. 1-168). Buenos Aires: Amorrortu.

Fromm, E. (1951). The Forgotten Language: An Introduction to the Understanding of Dreams, Fairy Tales, and Myths. New York: Open Road. 
Gadamer, H.-G. (1972). Die Unfähigkeit zum Gespräch. En H.-G. Gadamer, Hermeneutik II: Wahrheit und Methode. Ergänzungen und Register (Gesammelte Werke II) (pp. 207-215). Tübingen: J. C. B. Mohr.

Gaines, R. (1994). Interpersonal and Jungian dream interpretation. Contemporary Psychoanalysis, 30 (4), 855-867.

Gerson, S. (2004). The relational unconscious: A core element of intersubjectivity, thirdness, and clinical process. Psychoanalytic Quarterly, 73, 63-98.

Giannoni, M. (2003). Jung's theory of dream and the relational debate. Psychoanalytic Dialogues, 13 (4), 605-621.

Hill, D. (2015). Affect Regulation Theory: A Clinical Model. New York: W. W. Norton.

Howell, E. (2005). The Dissociative Mind. New York: Routledge

Howell, E. \& Itzkowitz, S. (Eds.) (2016). The Dissociative Mind in Psychoanalysis: Understanding and Working With Trauma. New York: Routledge.

Jung, C. G. (1928). Two Essays on Analytical Psychology. New York: The World.

Jung, C. (1945). De la esencia de los sueños. En C. Jung, La dinámica de lo inconsciente (OC 8) (pp. 281297). Madrid: Trotta.

Jung, C. G. (1995). Práctica de la psicoterapia: Contribuciones al problema de la psicoterapia y a la psicología de la transferencia. Madrid: Trotta.

Katz, G. (2014). The Play Within the Play: The Enacted Dimension of Psychoanalytic Process. New York: Routledge.

Kohut, H. (1971). Análisis del self: El tratamiento de los trastornos narcisistas de personalidad. Buenos Aires: Amorrortu.

Kohut, H. (1977). The Restoration of the Self. Chicago: Chicago University Press.

Kohut, H. (1982). Introspección, empatía y el semicírculo de la salud mental. En H. Kohut, Los dos análisis del Sr. Z (pp. 149-186). Barcelona: Herder.

Kohut, H. (1984). How Does Analysis Cure? Chicago: Chicago University Press.

Lichtenberg, J., Lachmann, F. \& Fosshage, J. (1992). Self and Motivational Systems: Toward a Theory of Psychoanalytic Technique. New York: Routledge.

Lichtenberg, J., Lachmann, F. \& Fosshage, J. (1996). The Clinical Exchange: Techniques Derived From Self and Motivational Systems. New York: Routledge.

Lichtenberg, J., Lachmann, F. \& Fosshage, J. (2011). Psychoanalysis and Motivational Systems: A New Look. New York: Routledge.

Loewald, H. (1960). On the therapeutic action of psychoanalysis. En H. Loewald, Papers on Psychoanalysis (pp. 221-256). New Haven: Yale University Press.

Mattoon, M. (1984). Understanding Dreams. Texas: Spring.

Mitchell, S. (1988). Relational Concepts in Psychoanalysis: An integration. Boston: Harvard University Press. 
Mitchell, S. (1993). Hope and Dread in Psychoanalysis. New York: Basic Books.

Mitchell, S. (1997). Psychoanalyse als Dialog: Einfluss und Autonomie in der analytischen Beziehung. Giessen: Psychosozial Verlag.

Orange, D. (1995). Emotionales Verständnis und Intersubjektivität: Beiträge zu einer psychoanalytischen Epistemologie. Frankfurt am Main: Brandes \& Apsel.

Orange, D. (2011). The Suffering Stranger: Hermeneutics for Everyday Clinical Practice. New York: Routledge.

Orange, D. (2016). Nourishing the Inner Life of Clinicians and Humanitarians: The Ethical Turn in Psychoanalysis. New York: Routledge.

Orange, D. (2020). Psychoanalysis, History, and Radical Ethics: learning to Hear. New York: Routledge.

Orange, D., Atwood, G. \& Stolorow, R. (1997). Intersubjektivität in der Psychoanalyse: Kontextualismus in der psychoanalytischen Praxis. Frankfurt am Main: Brandes \& Apsel.

Ricoeur, P. (1965). Die Interpretation: Ein Versuch über Freud. Frankfurt am Main: Suhrkamp Verlag.

Safran, J. (2006). The relational unconscious, the enchanted interior, and the return of the repressed. Contemporary Psychoanalysis, 42 (3), 393-412.

Sassenfeld, A. (2019 [2006]). Afecto, regulación afectiva y vínculo: Contornos de una perspectiva relacional sobre el desarrollo del self, la psicopatología y los procesos psicoterapéuticos. Berlin: Editorial Académica Española.

Sassenfeld, A. (2010a). Algunas reflexiones sobre la hermenéutica filosófica de Hans-Georg Gadamer y su relación con la práctica de la psicoterapia. Gaceta de Psiquiatría Universitaria, 6 (4), 427-448.

Sassenfeld, A. (2010b). Enactments: Una perspectiva relacional sobre vínculo, acción e inconsciente. Clínica e Investigación Relacional, 4 (1), 142-181.

Sassenfeld, A. (2012a). Principios clínicos de la psicoterapia relacional. Santiago de Chile: Ediciones SODEPSI.

Sassenfeld, A. (2012b). Gegenseitige Beeinflussung und Suggestion aus der Sicht einer verkörperten Intersubjektivitätstheorie. Psychoanalyse und Körper, 11 (2), 9-30.

Sassenfeld, A. (2012c). El desarrollo humano en la psicología analítica jungiana: Teoría e implicancias clínicas. Saarbrücken: Editorial Académica Española.

Sassenfeld, A. (2012d). Esbozo de una visión contemporánea de los afectos. Gaceta de Psiquiatría Universitaria, 8 (2), 174-191.

Sassenfeld, A. (2013). Verkörperte Intersubjektivität und sensomotorische Aspekte von Organisationsprinzipien der Subjektivität. Psychoanalyse and Körper, 22 (1), 11-42.

Sassenfeld, A. (2014). La intersubjetividad corporizada y aspectos sensoriomotrices de los principios organizadores de la subjetividad. Clínica e Investigación Relacional, 8 (2), 425-457.

Sassenfeld, A. (2016). El espacio hermenéutico: Comprensión y espacialidad en la psicoterapia analítica intersubjetiva. Santiago de Chile: Ediciones SODEPSI. 
Sassenfeld, A. (2019a). Los giros del psicoanálisis contemporáneo: Una introducción al psicoanálisis relacional. Santiago de Chile: RIL Editores.

Sassenfeld, A. (2019b). ¿Cómo funciona la mente clínica? Una contribución a la comprensión de la subjetividad de los psicoterapeutas desde la perspectiva del psicoanálisis relacional. Clínica e Investigación Relacional, 13 (2), 328-364.

Schore, A. (2003a). Affect Dysregulation and Disorders of the Self. New York: W. W. Norton.

Schore, A. (2003b). Affect Regulation and the Repair of the Self. New York: W. W. Norton.

Schore, A. (2012). The Science of the Art of Psychotherapy. New York: W. W. Norton.

Schore, A. (2019a). The Development of the Unconscious Mind. New York: W. W. Norton.

Schore, A. (2019b). Right Brain Psychotherapy. New York: W. W. Norton.

Scott-Baumann, A. (2009). Ricoeur and the Hermeneutics of Suspicion. London: Continuum.

Stern, D. B. (1997). Unformulated Experience: From Dissociation to Imagination in Psychoanalysis. New York: Psychology Press.

Stern, D. B. (2010). Partners in Thought: Working With Unformulated Experience, Dissociation, and Enactment. New York: Routledge.

Stern, D. B. (2015). Relational Freedom: Emergent Properties of the Interpersonal Field. New York: Routledge.

Stolorow, R. (2002). From drive to affectivity: Contextualizing psychological life. Psychoanalytic Inquiry, 22 (5), 678-685.

Stolorow, R. \& Atwood, G. (1982). Psychoanalytic phenomenology of the dream. Annual of Psychoanalysis, 10, 205-220.

Stolorow, R. \& Atwood, G. (1992). Contextos del ser: Las bases intersubjetivas de la vida psíquica. Barcelona: Herder.

Stolorow, R., Atwood, G. \& Orange, D. (2002). Worlds of Experience: Interweaving Philosophical and Clinical Dimensions in Psychoanalysis. New York: Basic Books.

Stolorow, R., Brandchaft, B. \& Atwood, G. (1987). Psychoanalytische Behandlung: Ein intersubjektiver Ansatz. Frankfurt am Main: Fischer Taschenbuch Verlag.

Tolpin, P. (1983). La psicología del self y la interpretación de los sueños. En G. Lancelle (Ed.), El self en la teoría y en la práctica (pp. 195-214). Buenos Aires: Paidós.

Winnicott, D. (1953). Transitional objects and transitional phenomena -A study of the first not-me possession. International Journal of Psychoanalysis, 34, 89-97.

Zeddies, T. (2000). Within, outside and in between: The relational unconscious. Psychoanalytic Psychology, 17, 467-487.

Original recibido con fecha: 13/12/2019 Revisado: 30/12/2019 Aceptado: 15/03/2020 
NOTAS:

${ }^{1}$ Para discusiones más detalladas de las diferencias entre hermenéutica de la sospecha y hermenéutica de la confianza en las que no puedo entrar aquí, véanse en especial Orange (2011) y Sassenfeld (2016).

${ }^{2}$ La base del argumento de Tolpin (1983) respecto de que no todos los sueños pueden ser considerados sueños del estado del self se basa en la idea de que existen pacientes con perturbaciones del self y pacientes sin perturbaciones del self. A mi entender, esa diferencia es algo que el mismo Kohut a partir de La restauración del self (1977) comenzó a desmantelar. Quizás, a estas alturas convendría hablar de los sueños como sueños del estado de la subjetividad del soñante, lo que nos remite a la original definición de Jung que ya discutimos.

${ }^{3}$ No es este el contexto para detallar el concepto de enactment, central para numerosos teóricos relacionales. Véanse Katz (2014) y Sassenfeld (2010b, 2012a, 2019). 